[3] Soriano L. C Contemporary epidemiology of gout in the UK general population. Arthritis Research \& Therapy 2011;13(6):39-48.

[4] Mazzalia M. Could uric acid have a pathogenic role in chronic allograft dysfunction. Arab Journal of Nephrology and Transplantation 2009;2 (3):37-41

Disclosure of Interest: None declared DOI: 10.1136/annrheumdis-2018-eular.3198

\section{AB1046 ALLOPURINOL USE IN CHRONIC KIDNEY DISEASE- IS THERE A DIFFERENCE IN ACHIEVING TARGET URIC ACID?- A RETROSPECTIVE STUDY}

V.R. Mehta ${ }^{1}$, R. Peredo-Wende ${ }^{2}$, R. Peredo-Wende ${ }^{2} .{ }^{1}$ Rheumatology; ${ }^{2}$ ALBANY MEDICAL CENTER, Albany, USA

Background: Patients with gout are recommended to treat to target uric acid level of $6 \mathrm{mg} / \mathrm{dL}$ in absence of tophi, and $<5 \mathrm{mg} / \mathrm{dL}$ if tophi present. A case-controlled retrospective analysis by Stamp et al of allopurinol hypersensitivity reaction confirmed that the highest risk of severe hypersensitivity reaction is in the first few months of therapy and thus a low starting dose is recommended (as low as $50 \mathrm{mg}$ in stage 4 chronic kidney disease and worse). Due to concerns related to adverse effects from Allopurinol, we hypothesised that allopurinol use would be less aggressive in terms of achieving target uric acid.

Objectives: We aim to compare the frequency of achieving target uric acid level in patients with glomerular filtration rate (GFR) of less than 60 and more than 60 . Methods: We reviewed charts of patients in a large private practice who were prescribed Allopurinol. Patients who had at least atleast two office visits and had been on Allopurinol at least six months were included in the study. Charts were reviewed of patients for uric acid level, Allopurinol dose, GFR and any major adverse events. Major allopurinol related adverse event was defined as any adverse event leading to hospitalisation or cessation of medication.

Results: Mean Allopurinol dose for patients with GFR of more than 60 was 244 . There were no major adverse events and 52 out of total 103 patients (50.5\%) had achieved goal uric acid.

Mean Allopurinol dose for patients with GFR of less than 60 was 238. There were no major adverse events and 19 out of total 38 patients $(50 \%)$ had achieved goal uric acid.

Conclusions: There was no difference noted in patient with GFR less than 60 or more than 60 in terms of achieving goal uric acid level. No major adverse events were noted in either group.

Disclosure of Interest: None declared

DOI: 10.1136/annrheumdis-2018-eular.7563

\section{Infection-related rheumatic diseases}

\section{AB1047 CERVICAL POTT'S DISEASE: 5 CASE REPORTS AND REVIEW OF LITERATURE}

A. Romdhane, N. Karmani, J. Kallel, I. Ben Said. Neurosurgery, National Institute of Neurology, Tunis, Tunisia

Background: Spinal tuberculosis (Pott's disease) is the most common as well as one of the most dangerous forms of skeletal tuberculosis and accounts for $50 \%$ of all cases of skeletal tuberculosis. Pott's disease is still common in developing countries. Although the thoracolumbar junction seems to be the most common site of the spinal column involvement, cervical localization is scarce and accounts for $2 \%$ to $5 \%$ of spinal tuberculosis. Furthermore, the incidence of neurologic complications in spinal tuberculosis varies from $10 \%$ to $43 \%$.

Objectives: The purpose of this study was to perform an updated review and present our experience with 5 cases of tuberculosis of cervical spine, including clinical characteristics, diagnostic modalities and management of spinal tuberculosis

Methods: A review of 5 cases of cervical Pott's disease collected at the Department of Neurosurgery of National Institute of Neurology of Tunis over a period of 2 years, between 2011 and 2012 and an updated literature review.

Results: The average age of our patients was 35 years old with extremes ranging from 16 to 63 years old. There is a slight male predominance. The diagnostic delay is on average 6 months. The clinical manifestations were dominated by cervical pain (4 cases) and progressive spinal cord compression syndrome (3 cases). The biological inflammatory syndrome is found in only one patient. The intra-dermal reaction to tuberculin is positive in 4 patients. X-ray of the cervical spine, CT scan and magnetic resonance imaging were performed in all patients. All patients underwent a surgical resection. The medical treatment was administered to all our patients. The evolution was favourable, clinically and biologically, under anti tubercular treatment.
Tuberculous spondylodiscitis remains a major global public health problem in endemic countries that affects mostly young adults in their most productive years. Thoracolumbar junction seems to be the most common site of the spinal column involvement in spinal tuberculosis (95\%) and cervical spine is concerned in only $5 \%$ of cases. The delayed diagnosis, between 3 and 20 months, explains the fre quency of neurological deficits which are found in proportions of $20 \%$ to $40 \%$. For the diagnosis of spinal tuberculosis, magnetic resonance imaging is more sensitive imaging technique than $\mathrm{x}$-ray and more specific than computed tomography. Antituberculous treatment remains the cornerstone of treatment. Surgery may be required in selected cases. With early diagnosis and early treatment, prognosis is generally good.

Conclusions: Cervical Pott's disease is a rare localization. The diagnosis is easy in front of the cervical signs. The conservative management of cervical spine immobilisation and antitubercular chemotherapy remains a sufficient attitude to healing. Surgery is reserved in case of neurological aggravation or spinal instability.

\section{REFERENCES}

[1] Jain AK. Tuberculosis of the spine: a fresh look at an old disease. J Bone Joint Surg Br 2010;92(7):905-13.

[2] Jain AK, Dhammi IK. Tuberculosis of the spine: a review. Clin Orthop Relat Res 2007:460(July):39-49.

[3] Boachie-Adjei O, Squillante RG. Tuberculosis of the spine. Orthop Clin North Am 1996;27(1):95-103.

[4] Dharmalingam M. Tuberculosis of the spine. the Sabah experience. Epidemiology, treatment and results. Tuberculosis (Edinb) 2004;84(1-2):24-8.

Disclosure of Interest: None declared

DOI: 10.1136/annrheumdis-2018-eular.3098

\section{AB1048 EVOLUTION OF INFECTIOUS SACROILIITIS ACCORDING TO THE GERM}

H. Ben Abla ${ }^{1,1,2}$, S. rekik ${ }^{2}$, S. boussaid ${ }^{2}$, H. ajlani ${ }^{2}$, H. sahli ${ }^{2}$, I. cheour ${ }^{2}$ M. elleuch ${ }^{2} .{ }^{1}$ rheumatology department, ${ }^{2}$ rheumatology departement, la rabta hospital, tunis, Tunisia

Background: infectious sacroiliitis is a rather rare rheumatological emergency that has a misleading semiology because of the deep condition of the joint, the germ responsible plays an important role in this semiology and in its evolution Methods: This is a retrospective study of 42 patients who have been hospitalised in the LA Rabta for Infectious Sacrolillitis from 1999 to 2017.the epidemiological data (age/sex) were recorded as well as the clinical radiolological and biologica data (symptoms, inflammatory assessment, $x$-rays, CT scan and/or IRM, biopsy). Results: fourty two patients were included in this study.the average age is 36,7 years old, sex distribution is: 19 women 23 men.

banal sprouts are responsible in $48.15 \%$ of cases: Staphylococcus aureus $28.7 \%$ eschirichia coli $17.07 \%$ and $2.38 \%$ streptococcus. the progression was favourable in $87.4 \%$ of the cases under appropriate antibiotic therapy for the rest: $2.38 \%$ deaths, $2.38 \%$ state of septic shock, $7.84 \%$ of complication inherent to the treatments.tuberculosis is responsible for $37.2 \%$ of infectious sacroiliitis with a favourable evolution in $77.6 \%$, a complication related to treatment is noted in $17.64 \%$, a subcutaneous abscess $2.34 \%$, mutifocal bone tuberculosis $2.38 \%$.brucellosis sacroiliitis is diagnosed in $14.65 \%$ of cases, the evolution is favourable in $7.51 \%$, in $4.76 \%$ a rapid progression towards ankylosis was noted despite appropriate antibiotic therapy, $2.38 \%$ a progression towards brucellosis chronic

Conclusions: common germs are most responsible during infectious sacroiliitis and seem to have the best prognosis, tuberculosis is responsible for various com plication and its treatment is at high risk of iatrogenic which limits the therapeutic choice of the clinician. chronicity is the most feared development during Brucella sacroillitis as antibiotic therapy is no longer effective

Disclosure of Interest: None declared

DOI: 10.1136/annrheumdis-2018-eular.7557

\section{AB1049 RHEUMATOLOGICAL MANIFESTATIONS DURING CHRONIC HEPATITIS C}

H. Kchir ${ }^{1}$, D. KAFFEL ${ }^{2}$, H. Dabbebi ${ }^{1}$, D. ISSAOUI ${ }^{1}$, H. Sahli ${ }^{3}$, W. Hamdi ${ }^{2}$ M. Elleuch ${ }^{3}$, M.M. Kchir ${ }^{2}$, R. Debbeche ${ }^{4}$, N. Maamouri ${ }^{1} .{ }^{1}$ Gastroenterology, La Rabta Hospital, Tunis; ${ }^{2}$ Rhematology, Kassab, Manouba; ${ }^{3}$ Rhematology, La Rabta Hospital; ${ }^{4}$ Gastroenterology, Charles Nicolle Hospital, Tunis, Tunisia

Background: Chronic hepatitis $\mathrm{C}(\mathrm{CHC})$ is assimilated to a systemic disease because of his multiple extrahepatic manifestations notably rheumatological. Objectives: The aim of this study was to determinate the prevalence and the characteristics of rheumatological manifestations (RM) associated with $\mathrm{CHC}$. 